\title{
COVID-19: The outbreak caused by a new coronavirus
}

\author{
Erika Sifuentes-Rodríguez ${ }^{1 *}$ and Deborah Palacios-Reyes ${ }^{2}$ \\ ${ }^{1}$ Servicio de Pediatría, Hospital Ángeles Lomas; ${ }^{2}$ Servicio de Parasitología y Micología, Instituto Nacional de Pediatría. Mexico City, Mexico
}

\begin{abstract}
Before the severe acute respiratory syndrome outbreak in 2003, coronaviruses (CoVs) were not considered to be highly pathogenic to humans. However, it was this epidemic that highlighted this group of viruses and included them among the causative agents of emerging epidemic diseases. In addition, in 2012, another new CoV responsible for the Middle East respiratory syndrome was identified. Both infections were considered a threat to global health security. At present, the third epidemic caused by a CoV is being faced. This new CoV, called 2019-nCoV, was originated in the city of Wuhan, China, and has been linked to severe respiratory infections in humans. Thanks to the collaboration of experts worldwide, more information about this virus and its infection is reported each day, which allows modifying the recommendations for its prevention and treatment, without forgetting that the ultimate goal is to control this epidemic. In this review, the important aspects of this new coronavirus, 2019-nCoV, and its disease, COVID-19, have been summarized with the information available up to February 2020.
\end{abstract}

Key words: Coronavirus. Emerging epidemic diseases. Coronavirus disease 2019. Middle East respiratory syndrome coronavirus. Severe acute respiratory syndrome coronavirus.

\section{COVID-19: la epidemia causada por un nuevo coronavirus}

\section{Resumen}

Previo al brote del síndrome respiratorio agudo grave de 2003, los coronavirus (CoV) no eran considerados como agentes altamente patogénicos para los humanos. Sin embargo, fue dicha epidemia la que destacó este grupo de virus y lo incluyó entre los agentes causantes de enfermedades epidémicas emergentes. Adicionalmente, en 2012 se identificó un nuevo CoV causante del síndrome respiratorio de Oriente Medio. Ambas infecciones fueron consideradas una amenaza para la seguridad sanitaria mundial. Hoy en día se presenta la tercera epidemia causada por un CoV. Este nuevo CoV, Ilamado 2019-nCoV, se originó en la ciudad de Wuhan, China, y ha sido relacionado con infecciones respiratorias graves en humanos. Gracias a la colaboración de expertos en todo el mundo, cada día se logra obtener más información sobre este virus y la infección que causa, lo cual permite modificar las recomendaciones para su prevención y tratamiento sin olvidar que el fin último es lograr el control de la epidemia. En esta revisión se resumen los aspectos más importantes acerca del nuevo 2019-nCoV y la enfermedad COVID-19, con la información disponible hasta febrero de 2020.

Palabras clave: Coronavirus. Enfermedades epidémicas emergentes. COVID-19. MERS-CoV. SARS-CoV.

\section{Correspondence:}

*Erika Sifuentes-Rodríguez

E-mail: dra.erikasifuentes@gmail.com

DOI: 10.24875/BMHIM.20000039
Available online: 23-03-2020 Bol Med Hosp Infant Mex. 2020;77(2):47-53 www.bmhim.com 1665-1146/C 2020 Hospital Infantil de México Federico Gómez. Published by Permanyer. This is an open access article under the CC BY-NC-ND license (http://creativecommons.org/licenses/by-nc-nd/4.0/). 


\section{Introduction}

In December 2019, a group of patients with pneumonia of unknown cause, epidemiologically linked to a live animal market in Wuhan, Hubei Province in China, began to be reported ${ }^{1,2}$. These cases were identified by local hospitals using a surveillance method for "pneumonia of unknown cause" that was established following the outbreak of severe acute respiratory syndrome (SARS) in 2003, to allow timely identification of new pathogens ${ }^{3}$.

By December 31, 2019, the Centers for Disease Control and Prevention (CDC China) initiated an epidemiological investigation. For this purpose, three adult patients with severe pneumonia who were admitted to Wuhan hospital on December 27, 2019, were selected. Bronchoalveolar lavage samples were taken from each of them, and 22 pathogens (18 viruses and 4 bacteria) were searched using the RespiFinderSmart-22 kit, in which none of the samples had pathogen isolation. Subsequently, RNA was extracted from the bronchoalveolar fluid and used as a model for cloning and sequencing a genome by combining two methods. More than 20,000 viral readings were obtained from individual samples, which showed compatibility with the lineage of the genus beta-coronavirus (CoV). Virus isolation was achieved in human airway epithelial cells and Vero E6 and Huh-7 cell lines. In addition, cytopathic effects produced by this virus were observed after $96 \mathrm{~h}$ of being inoculated into human airway epithelial cells. The new virus isolated was named 2019-nCoV1.

Subsequently, operational procedures and primers were shared with the World Health Organization (WHO) for surveillance and detection of 2019-nCoV infection in China and the rest of the world.

On January 30,2020 , the WHO declared that the outbreak of the new coronavirus (2019-nCoV) was a public health emergency of international concern due to the increasing number of confirmed cases, not only in China but in other countries. The main objective of this declaration was to prepare nations and unify efforts to respond to this epidemic ${ }^{4-7}$ (Fig. 1).

\section{CoV}

The first knowledge about human CoVs (HCoVs) dates back to 1965 . This new group of viruses was then called CoVs due to the projections observed on their surface, which resembled a crown (in Latin corona). CoVs are positive-strand RNA viruses of 26 to $32 \mathrm{~kb}$ in length, for which are the largest RNA viruses known currently. They belong to the family Coronaviridae and can infect humans and a wide variety of animals, causing asymptomatic infections or respiratory, gastrointestinal, and neurological infections ${ }^{9}$. In humans, the severity of these infections varies. CoV respiratory infections are considered to be frequent, with upper airway infection being the most common type of illness, and sporadic cases of pneumonia in children or adults $^{9,10}$. CoV infection can occur at any age, but it is more common in children. As other respiratory viruses, reinfection is common.

According to their phylogenetic analysis and antigenic criteria, CoV can be divided into four genera called alpha-, beta-, delta-, and gamma-CoV ${ }^{11}$. Before the description of this new virus, six CoVs were known to be capable of infecting humans: two alpha-CoVs (HCoV-229E and HCoV-NL63) and four beta-CoVs (HCOV-OC43, HCoV-HKU1, SARS-CoV, and Middle East respiratory syndrome [MERS]-CoV). In addition, four types of CoV, 229E, OC43, NL63, and HKU1 are globally endemic and commonly involved in respiratory infections. It should be mentioned that these four types rarely cause severe respiratory illness and are, therefore, typically associated with the common cold ${ }^{10}$. The $\mathrm{HCoV} \mathrm{OC} 43$ (HCoV-43) is the most prevalent of all, especially in children and elderly adults.

\section{SARS and MERS}

The importance of CoVs at a public health level emerged in the $21^{\text {st }}$ century, with the identification of two new types of beta-CoVs, SARS-CoV and MERS-CoV, which cause severe respiratory syndrome ${ }^{9}$.

In April 2003, a previously unidentified CoV was reported as the causal agent of an outbreak in patients with SARS, which became known as SARS-CoV'2. The SARS outbreak occurred in Southern China: since November 2002, there have been more than 8000 cases and a total of 774 deaths in multiple countries, with most cases occurring in Hong Kong. It was a zoonotic infection, where the transmission of SARS-CoV to humans occurred through masked palm civets (a carnivorous mammal species with Asian distribution) and other live animals in Chinese markets ${ }^{10}$. The last reported cases occurred in January 2004; no new cases of SARS have been detected since.

After 9 years, in June 2012, the CoV causing MERS was identified as the causal agent of a group of cases with severe respiratory syndrome in Jordan. MERS-CoV emerged and spread to other countries outside the Arabian Peninsula ${ }^{12}$. After extensive research, it was 


\section{COVID-19}

Huanan Market in Wuhan City is closed. - 01. JAN

China shares the sequence of the new virus for the development of diagnostic tests in any country.

Forty-one cases have been diagnosed with 2019-nCoV infection in Wuhan. 12. JAN

Japan confirms its first case for 2019-nCoV with a background of travel to Wuhan. - 15. JAN

Korea reports the first case of 2019-nCoV infection. - 20. JAN

WHO declares public health emergency for 2019-nCoV infection - 31. JAN
08. DEC - Emergence of the first cases of pneumonia of unknown cause in Wuhan City, China

29. DEC - Identification of the first 4 cases associated with the Huanan food market

31. DEC - CDC China initiates epidemiological investigation led by the cluster of cases.

WHO issues an epidemiological alert due to an unknown agent, cases linked to the Huanan live animal market.
13. JAN - Thailand confirmed the first imported case of 2019-nCoV infection.

07. JAN - CDC China confirmed the identification of a new coronavirus (2019-nCoV) as a possible cause of the pneumonia outbreak.

16. JAN - Wuhan introduces strict measures for people leaving the city.

21. JAN - CDC China shares reagents and primers for the diagnosis of 2019-nCoV.

Figure 1. Chronological development of coronavirus disease 2019.

determined that camels transmitted MERS-CoV to humans and remain as reservoirs of MERS-CoV. According to the WHO reports, the last confirmed case was reported in October 2019 in the United Arab
Emirates, with a total of 2499 cases reported up to December 2019.

Both SARS-CoV and MERS-CoV have an incubation period of 5 days; $95 \%$ of patients develop the disease 
within 13 days after viral exposure. It is more common for patients infected with MERS-CoV to require intensive care, compared to those reported with SARS-CoV (50$89 \%$ vs. $20-30 \%$, respectively). The mortality rate reported for MERS-CoV is $36 \%$, while for SARS-CoV is $10 \%{ }^{12}$.

\section{9-nCoV}

2019-nCoV is a new type of beta-CoV, belonging to the subgenus Sarbecovirus ${ }^{13}$. Once this new virus was identified and its entire genome sequenced, an extensive search was performed in the GenBank genetic sequence database, where it was found to be mostly related to two bat CoV strains (bat-SL-CoVZC45 and bat-SL-CoVZXC21), with $96.2 \%$ homology with the first one. Significantly, $2019-n$ CoV shares only $79.5 \%$ of its genetic sequence with SARS-CoV, and approximately $50 \%$ with MERS-CoV ${ }^{1,13}$. Therefore, it is considered that, as occurred with SARS-CoV and MERS-CoV, the origin of this virus is a bat $\mathrm{CoV}$, which crossed the species barrier and finally infected humans. However, so far, it has not been possible to establish which animals are the reservoir hosts. In addition, human-to-human transmission has been confirmed by the presence of cases among family members and health workers.

At the time of preparation of this review, based on initial assessments of the epidemiological characteristics, 2019-nCoV has been estimated to have an incubation period of 5.2 days $(95 \%$ confidence interval [Cl], 4.1-7.0). The growth rate of the epidemic has been considered to be 0.10 per day $(95 \% \mathrm{Cl} 0.050-0.16)$; thus, a period of 7.4 days has been calculated for the number of cases to double. On average, it is estimated that each patient is responsible for infecting other 2.2 individuals (infection rate $\left[\mathrm{R}_{0}\right] 2.2[95 \% \mathrm{Cl}, 1.4-3.9)$. At present, the reported mortality rate for $2019-\mathrm{nCoV}$ is $2.6 \%{ }^{13}$.

The WHO report up to February 13, 2020, announced 46,997 confirmed cases, of which 46,550 are concentrated in China and the rest of the cases (447) in 24 other countries. A total of 1114 deaths have been reported, all recorded in China, except for one death in the Philippines. From the Americas, only the United States and Canada have confirmed cases (21 in total). At present, all transmissions have occurred within groups with known cases ${ }^{6}$.

\section{Clinical presentation}

The clinical spectrum of coronavirus disease 2019 (COVID-19) consists mainly in the development of pneumonia, similar to SARS and MERS, which are characterized by the involvement of the lower respiratory tract causing discrete symptoms at the upper airway (sneezing, rhinorrhea, and odynophagia) ${ }^{14}$. However, asymptomatic infection has already been demonstrated ${ }^{15}$. To date, the main symptoms presented by patients with COVID-19 are fever, cough, myalgia, fatigue, expectoration, headache, and gastrointestinal symptoms such as diarrhea. The gastrointestinal involvement is observed in a lower percentage in comparison with MERS. Approximately half of the patients show dyspnea, which usually occurs 8 days after the onset of symptoms. Severe cases have developed significant hypoxemia, requiring oxygen supply by highflow devices; additionally, up to $30 \%$ of cases require to be transferred to an intensive care unit ${ }^{14,16,17}$.

Radiological findings from high resolution computed tomography of the lung are characterized by bilateral affection, either with images in ground-glass opacities or lobar or subsegmental consolidations.

Regarding laboratory studies, leukopenia may be present, although most patients show lymphopenia. They may also present elevated transaminases and troponin I levels, which have been reported in patients who presented heart failure as a complication of COVID-19 ${ }^{14,16}$. Acute-phase reagents such as C-reactive protein and erythrocyte sedimentation rate are elevated, but with negative procalcitonin in most cases, except for those who develop bacterial secondary infections ${ }^{14}$.

Although the entire population is susceptible to be infected with 2019-nCoV, the most affected population is concentrated in adulthood (mean age for the first 41 cases: 49 years [95\% Cl] 41.0-58.0) and males ${ }^{14}$. So far, pediatric patients have shown a benign course, and no deaths have been recorded in children. In this group of age, patients could be asymptomatic or the clinical picture may include fever, dry cough, and fatigue; upper respiratory tract symptoms, such as nasal congestion and rhinorrhea; and gastrointestinal symptoms (nausea, vomiting, diarrhea, and abdominal pain), which are seen more often compared to adults. Progression to pneumonia occurs in a few cases; however, pediatric cases are scarce to make further claims regarding the risk of complications and death ${ }^{18,19}$. No evidence of intrauterine infection caused by vertical transmission in the case of pregnant women has been observed ${ }^{20}$.

Elderly adults and patients with comorbidities, such as diabetes, cardiovascular disease, and asthma, are at higher risk of developing severe pneumonia and complications associated with COVID-1914,16. 


\section{According to the USA CDC a patient who meets the following criteria should be evaluated as a patient under investigation for 2019-nCoV}

\section{Clinical features}

Fever or signs/symptoms of lower respiratory disease (e.g. coughing or dyspnea)

Fever or signs/symptoms of lower respiratory disease (e.g. cough or dyspnea).

Fever or signs/symptoms of lower respiratory illness (e.g. cough or dyspnoea) requiring hospitalisation.

\section{Epidemiological risk}

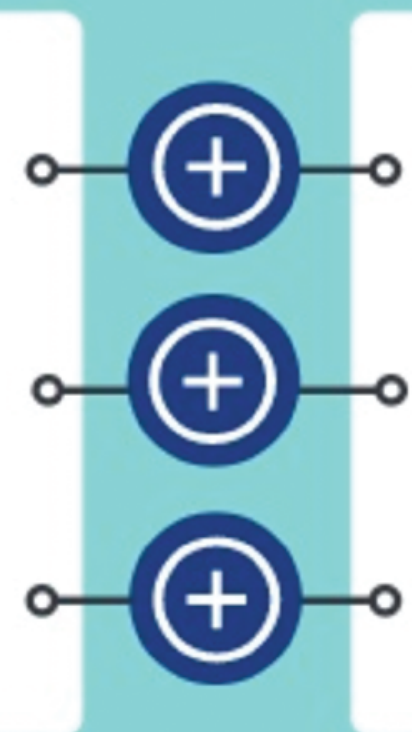

Any person, including healthcare personnel, who has had direct contact with a patient confirmed positive by laboratory for 2019-nCoV, up to 14 days before the onset of symptoms.

History of travel to Hubei Province, China, up to 14 days before onset of symptoms

History of travel from anywhere in China up to 14 days before onset of symptoms.

\section{According to the National Committee for Epidemiological Surveillance (CONAVE)* in Mexico, the operational definitions are the following}

\section{Suspected case}

Acute respiratory disease

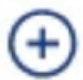

Travel history or stay in Hubei, China or have been in contact with a confirmed or investigated case, up to 14 days before the onset of symptoms
Confirmed case

Person who meets the operational definition of a suspicious case.

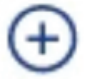

Laboratory-confirmed diagnosis issued by the Institute for Diagnostic and Epidemiological Reference (InDRE)**

Adapted from CDC and Mexico General Office of Epidemiology***

Figure 2. Criteria for the evaluation of patients with suspected coronavirus disease 2019.

* Comité Nacional para la Vigilancia Epidemiológica (CONAVE).

** Instituto de Diagnóstico y Referencias Epidemiológicas (InDRE).

***Dirección General de Epidemiología de México.

The complications reported so far are acute respiratory distress syndrome, RNAemia, acute heart failure, and secondary infections. Agents that have been isolated in critically ill patients with the latter complication are Acinetobacter baumannii, Klebsiella pneumoniae, Aspergillus flavus, Candida glabrata, and Candida albicans. Mortality due to COVID-19 increases considerably in the elderly, obese, and patients with comorbidities. The causes of death have been severe pneumonia with respiratory failure and septic shock ${ }^{14,16}$. 


\section{Treatment}

The management of patients with COVID-19 requires support measures, according to the clinical condition of each patient.

Based on the evidence of the cytokine-mediated inflammatory response shown in other $\mathrm{CoV}$ infections (SARS-CoV and MERS-CoV), the use of corticosteroids has been suggested in patients with COVID-19. Studies in SARS and MERS patients showed that steroids did not decrease the mortalityrate; on the contrary, steroids were able to prolong the elimination of the virus. Therefore, the current WHO and CDC recommendation for the management of COVID-19 is not to administer systemic corticosteroids routinely; however, evidence should be expanded to support this recommendation ${ }^{16}$.

To date, no antiviral treatment has shown to be effective in treating CoVs. Antiviral drugs such as interferon-alpha and lopinavir/ritonavir (protease inhibitor and its booster), which have previously been shown to be effective in SARS and MERS, have been used in COVID-19 cases. Remdesivir, which acts as a nucleoside analog, is a broad-spectrum antiviral currently considered the best therapeutic option ${ }^{2,16,21}$.

\section{Prevention}

Due to the current evidence of human-to-human transmission, it is necessary to establish precautionary measures. For patients in the community with suspected COVID-19, the recommendation is to use a surgical mask and to remain in isolation. Since more than 500 physicians and health-care personnel in China have contracted the virus, the WHO recommends the use of surgical masks and eye protection, as well as standard precautionary measures for the management of patients with suspected or confirmed COVID-1922,23. Only in the procedures that generate aerosols (e.g., orotracheal intubation, cardiopulmonary resuscitation, or bronchoscopy), it is recommended to use N95 masks or respirators. The recommendation issued by the CDC is the isolation of patients inside negative pressure rooms; if this is not possible, it is recommended to keep them in separate rooms with closed doors and the use of a mask. Health-care personnel in charge of COVID-19 patients must use the appropriate equipment each time when entering the rooms; i.e., the use of N95 masks, gowns, gloves, and eye protection ${ }^{24}$.
Regarding the prevention of exposure to 2019-nCoV for the general population, the following recommendations have been issued:

- Handwashing with soap and water or hand hygiene with alcohol gel at concentrations higher than $70 \%$ when hands are not visibly dirty

- Respiratory hygiene, which refers to covering the nose and mouth with the bent elbow or with a disposable tissue when sneezing or coughing, followed by tissue disposal and hand hygiene

- To keep a distance of $1 \mathrm{~m}$ from people who are coughing, sneezing or have a fever

- Avoid touching the eyes, nose, or mouth

- Seek medical attention if symptoms such as fever, cough, or respiratory distress are noticed, or if you have been in direct contact with patients with a history of travel to China and show respiratory symptoms ${ }^{23}$.

\section{Epidemiological surveillance in Mexico}

According to the epidemiological estimates of this infection, there is a risk of a pandemic. In January, 2020 , when the WHO issued the declaration of this public health emergency of international concern, it also declared that its greatest concern is the potential spread of this virus to countries with weaker health systems ${ }^{25,26}$. Mexico is undoubtedly considered to be among these countries. However, the Dirección General de Epidemiología (General Office of Epidemiology), as part of the Secretaría de Salud (Ministry of Health), published the Standardized Guidelines for Epidemiological and Laboratory Surveillance of 2019nCoV disease, with the main objective of detecting cases and risks in our country ${ }^{27}$. In these guidelines, specific procedures can be found for a suspected case of infection with 2019-nCoV and measures for epidemiological surveillance for practicing physicians in Mexico (Fig. 2).

Finally, as physicians, we have the responsibility to properly inform the population; therefore, in public health emergencies, it is extremely important to avoid misinformation. Consequently, the medical community is invited to promote the use of the COVID-19 validated information.

\section{Conflicts of interest}

The authors declare that they have no conflicts of interest. 


\section{Funding}

None.

\section{References}

1. Zhu N, Zhang D, Wang W, Li X, Yang B, Song J, et al. A novel coronavirus from patients with pneumonia in China, 2019. N Engl J Med. 2020;382:727-33

2. Del Rio C, Malani PN. 2019 novel coronavirus-important information for clinicians. JAMA. 2020, ahead of print.

3. Li Q, Guan X, Wu P, Wang X, Zhou L, Tong Y, et al. Early transmission dynamics in Wuhan, China, of novel coronavirus-infected pneumonia. $\mathrm{N}$ Engl J Med. 2020, ahead of print.

4. World Health Organization. Vigilancia Mundial de la Infección Humana Por el Nuevo Coronavirus (2019-nCoV). Geneva: World Health Organization; 2020.

5. World Health Organization. Novel Coronavirus (2019-nCoV) Situation Report-1. Geneva: World Health Organization; 2020. p. 1-5.

6. World Health Organization. Coronavirus Disease 2019 (COVID-19) Situation Report-23. Geneva: World Health Organization; 2020.

7. Patel A, Jernigan DB, 2019-nCoV CDC Response Team. Initial public health response and interim clinical guidance for the 2019 novel coronavirus outbreak-United States, December 31, 2019-February 4, 2020. MMWR Morb Mortal Wkly Rep. 2020;69:140-6.

8. Kahn JS, Mclntosh K. History and recent advances in coronavirus discovery. Pediatr Infect Dis J. 2005;24:S223-7, discussion S226.

9. Paules $\mathrm{Cl}$, Marston HD, Fauci AS. Coronavirus infections-more than just the common cold. JAMA. 2020, ahead of print.

10. Cui J, Li F, Shi ZL. Origin and evolution of pathogenic coronaviruses. Nat Rev Microbiol. 2019;17:181-92.

11. Ceraolo C, Giorgi FM. Genomic variance of the 2019-nCoV coronavirus. J Med Virol. 2020, ahead of print.

12. de Wit E, van Doremalen N, Falzarano D, Munster VJ. SARS and MERS: recent insights into emerging coronaviruses. Nat Rev Microbiol. 2016;14:523-34.

13. Lu R, Zhao X, Li J, Niu P, Yang B, Wu H, et al. Genomic characterisation and epidemiology of 2019 novel coronavirus: implications for virus origins and receptor binding. Lancet. 2020;395:565-574.
14. Huang C, Wang Y, Li X, Ren L, Zhao J, Hu Y, et al. Clinical features of patients infected with 2019 novel coronavirus in Wuhan, China. Lancet. 2020;395:497-506.

15. Chan JF, Yuan S, Kok KH, To KK, Chu H, Yang J, et al. A familial cluster of pneumonia associated with the 2019 novel coronavirus indicating person-to-person transmission: a study of a family cluster. Lancet. 2020;395:514-523.

16. Chen N, Zhou M, Dong X, Qu J, Gong F, Han Y, et al. Epidemiological and clinical characteristics of 99 cases of 2019 novel coronavirus pneumonia in Wuhan, China: a descriptive study. Lancet. 2020;395: $507-13$.

17. Wang D, Hu B, Hu C, Zhu F, Liu X, Zhang J, et al. Clinical characteristics of 138 Hospitalized patients with 2019 novel coronavirus-infected pneumonia in Wuhan, China. JAMA. 2020, ahead of print.

18. Chen ZM, Fu JF, Shu Q, Chen YH, Hua CZ, Li FB, et al. Diagnosis and treatment recommendations for pediatric respiratory infection caused by the 2019 novel coronavirus. World J Pediatr. 2020, ahead of print.

19. Shen K, Yang $Y$, Wang T, Zhao D, Jiang $Y$, Jin R, et al. Diagnosis, treatment, and prevention of 2019 novel coronavirus infection in children: experts' consensus statement. World J Pediatr. 2020, ahead of print.

20. Chen H, Guo J, Wang C, Luo F, Yu X, Zhang W, et al. Clinical characteristics and intrauterine vertical transmission potential of COVID-19 infection in nine pregnant women: a retrospective review of medical records. Lancet. 2020, ahead of print.

21. Lu H. Drug treatment options for the 2019-new coronavirus (2019-nCoV). Biosci Trends. 2020, ahead of print.

22. Organización Panamericana de la Salud (OPS). Alerta Epidemiológica- Nuevo Coronavirus (nCoV). Washington, DC: Organización Panamericana de la Salud; 2020. p. 1-4.

23. World Health Organization. COVID-19 Protective Measures; 2020. Available from: https://www.who.int/health-topics/coronavirus.

24. Centers for Disease Control and Prevention. Interim Infection Prevention and Control Recommendations for Patients with Confirmed 2019 Novel Coronavirus. USA: Centers for Disease Control and Prevention; 2019.

25. Zarocostas J. What next for the coronavirus response? Lancet. 2020;395:401.

26. Phelan AL, Katz R, Gostin LO. The novel coronavirus originating in Wuhan, China: challenges for global health governance. JAMA. 2020, ahead of print.

27. Dirección General de Epidemiología. Lineamiento Estandarizado Para la Vigilancia Epidemiológica y Por Laboratorio de Enfermedad Por 2019nCoV. Mexico: Dirección General de Epidemiología; 2020. 